\section{Human Rights and Family Planning}

SIR,-I am sorry to read (Supplement, 4 April, p. 8) that the Public Health Conference referred to the Public Health Committee a motion on family planning involving "identification and follow up (italics mine) of individuals who may fail to provide satisfactory parental care." The intentions are clear. One speaker, Dr. J. T. Clow, was perhaps more percipient than the Conference, considering it unwise "in terms of the freedom of the individual."

Pregnancies may be unwanted but they can hardly be said to be unforeseeable. Unplanned pregnancies are now equated far too readily with unwanted babies and congenital delinquency, etc. Mr. Douglas Houghton $^{1}$ obviously believes the State should intervene to require family limitation, though he acknowledges the difficulty of reconciling this with declarations of human rights.

If this resolution is accepted by the B.M.A. in its present form, we will be accepting the right of the State to intervene in the most personal individual rights. I hope wiser counsels will prevail.-I am, etc.,

\section{Exeter,}

E. D. IRVINE.

\section{REFERENCE}

1 Houghton, D., Medical Officer, 1970, 123, 175.

\section{Differentiation between Diverticulitis and Diverticulosis}

SIR,-No one would disagree that there are limitations to the radiological differentiation of diverticulosis and diverticulitis, especially if the now outmoded traditional criteria are used, and it is not surprising that this is confirmed by Mr. T. G. Parks and his colleagues. (18 April, p. 136).

Their suggestion that it is only now that more definite criteria for the diagnosis of inflammatory changes in diverticular disease are being sought by radiologists is misleading. Such criteria were described in detail by Wolf, Khilnani, and Marshak $^{1}$ over 12 years ago. Indeed, the penultimate paragraph in the discussion by $\mathrm{Mr}$. Parks and his colleagues resembles a précis of this work.

The observer variability study by $\mathrm{Mr}$. Parks and colleagues includes the agreement between three radiologists, one having made a report using now discarded criteria, and the other two using modern criteria. For example, a jagged or saw-toothed configuration on barium enema, now attributed to a muscular abnormality, was previously regarded as a sign of diverticulitis. Disagreement under such circumstances is only to be expected.-I am, etc.,

\section{H. C. Anton.}

Stobhill Hospital, Glasgow.

\section{REFFRENCE}

1 Wolf, B. S., Khilnani, M., and Marshak, R. H., American fournal of Roentgenology Radium
Therapy and Nuclear Medicine, 1957, 77, 726.
SIR,-Dr. K. F. R. Schiller and others (4 April, p. 7) have given a constructive assessment of the problems of management of acute gastrointestinal bleeding. In particular their observations on the place of vagotomy, drainage, and local ligation of the bleeding point are valuable. Could they, however, enlarge on their experience of recurrent bleeding? Firstly, how much blood had to be given for recurrent bleeding whether a second operation was required or not? Secondly, how many, if any, patients with recurrent bleeding required a second emergency operation? Thirdly, of the $37 \%$ of patients who died after recurrent bleeding, what proportion of these had a second emergency operation? Fourthly, in the $37 \%$ of fatal recurrent haemorrhages, how many of these followed vagotomy and drainage for duodenal ulcer cases?

I have sugested elsewhere ${ }^{1}$ that if a genuine emergency operation (rather than an early elective operation) is thought necessary for haemorrhage, three objectives should be in the mind of the surgeon. The first is to save life by arresting haemorrhage. The second is to create, if possible, conditions which will protect against early re-bleeding. The third is to attempt to cure peptic ulceration. Quite often all three desirable criteria can be fulfilled.

There are many reports of encouraging results in the management of bleeding duodenal ulcer by vagotomy, drainage, and local ligation of the bleeding point, but these (particularly in American series) often include a preponderence of "early elective" procedures. With the large penetrating pos- terior duodenal ulcer submitted to urgent operation the risk of re-bleeding may be high if the ulcer is left in situ in contact with gastric and duodenal secretions and ligated either with catgut, which might digest too soon, or with non-absorbable material, which may help to perpetuate the condition. Further, vagtomy, even in the best hands, is inadequate in more than $10 \%$ of cases ${ }^{2}$ and probably even less successful in emergency operations.

I am, of course, well aware of the immediate hazards and late complications of more extensive procedures such as emergency partial gastrectomy. I would admit also that a shift to vagotomy and drainage for bleeding duodenal ulcer is perhaps forced on us at present because the average senior registrar or young consultant has now little or no experience of performing partial gastrectomy electively for the difficult duodenal ulcer. The history of the management of bleeding duodenal ulcer reveals over the years, how emergency surgery has paralleled the current fashion of elective surgery. Perhaps we should be a little wary of applying contemporary, orthodox, elective procedures wholesale to. emergency cases of bleeding (or, for that matter, cases of perforation) because each case presents very much as an individual problem.-I am, etc.,

\section{Liverpool.

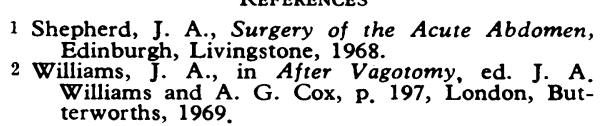 terworths, 1969 .}

JOHN A. SHEPHERD.
SIR,-I write to congratulate Mr. J. L Provan for his letter (18 April, p. 180) and Dr. I. M. Jones and his panel for their document Health Services Financing (Supplement, 18 April, p. 41). Mr. Provan proposes that there should be an increase in the number of consultants in the National Health Service, but points out that this would be difficult to bring about unless further finanice becomes available for the Service. Dr. Jones and his panel also reach the conclusion that additional finance is required for the Service, and point out that this will never be available from Government revenue.

Unfortunately, there are practical difficulties in the way of both Mr. Provan's and Dr. Jones's proposals, stemming from the nature of the medical profession. Thus $\mathrm{Mr}$. Provan's proposals are not materially different from those of the Godber working party which have already been rejected as a basis for discussion by the profession. ${ }^{2}$ This rejection I understand to have been not entirely owing to the lack of finance. Dr. Jones's conclusions have not been controversial among many people interested in the financing of medical care for many years. The same conclusion was put clearly to the profession by a former Minister of Health, $\mathrm{Mr}$. Enoch Powell, some years ago. Once again, however, the profession's attitude is divided, since many of us appear to object to the raising of funds other than by
Government impost.

The majority of the profession will always have little or no interest in medical administration and politics. This might be desirable if it were not for the fact that the profession as a consequence tends to have either no thought-out attitude or an internally contradictory one when faced with crucial but controversial issues such as staffing and finance. If this state of affairs persists, it would seem to be not unreasonably pessimistic to anticipate a gradual deterioration in the quality of the medical services in this country over the next 20 or 30 years until the situation is beyond repair. During this period there would presumably be continued efforts to paper over the cracks in the Service, but there would be no fundamental reform. Not unless there were to be a clear-cut crisis in medical care which the public could appreciate would an attempt be made to take effective steps. Should such a crisis occur, it would then be too late to resolve it.

It is very much to be hoped, therefore, that the profession will support the Joint Consultants Committee's principles with respect to medical staffing in hospitals (on which negotiation is now taking place with the Department of Health) and also the general proposition set out in Health Services Financing. An adjustment of the medical staffing structure in hospitals and the contractual basis for the employment 